\title{
As manifestações da Corrente Positivista na Educação Científica
}

\section{The manifestations of the Positivist Current in Scientific Education \\ Las manifestaciones de la Corriente Positivista en la Educación Científica}

Dennis Bezerra Correia

ORCID: https://orcid.org/0000-0002-7782-4767 Universidade Regional do Cariri, Brasil E-mail: denniscorreia40@gmail.com

Catarina Leite Gurgel

ORCID: https://orcid.org/ 0000-0003-2572-2205

Universidade Federal Rural de Pernambuco, Brasil

E-mail: catarinaleite06@gmail.com

Rivânia Silva Alves

ORCID: https://orcid.org/ 0000-0003-1434-8086 Universidade Regional do Cariri, Brasil E-mail: rivaniasalves@yahoo.com.br

Filipe Gutierre Carvalho de Lima Bessa ORCID: https://orcid.org/0000-0001-8126-8831

Universidade Estadual Vale do Acaraú, Brasil E-mail: filipe_carvalho@uvanet.br

Cicero Magerbio Gomes Torres

ORCID: https://orcid.org/ 0000-0002-3585-452X Universidade Regional do Cariri, Brasil E-mail: cicero.torres@urca.br

Gledson Ferreira Macedo

ORCID: https://orcid.org/ 0000-0002-2609-6894 Universidade Federal do Cariri, Brasil

E-mail: gled_fer@yahoo.com.br

Kleber Ribeiro Fideli

ORCID: https://orcid.org/ 0000-0002-2507-1468

Universidade Federal de Pernambuco, Brasil

E-mail: kleberfidelis0@gmail.com

Francileide Vieira Figueirêdo

ORCID: https://orcid.org/ 0000-0002-6853-854X

Universidade Regional do Cariri, Brasil

E-mail: francileidevf@gmail.com

Samuel Wagner Tiburi Silveira

ORCID: https://orcid.org/ 0000-0001-8324-9829

Universidade Regional do Cariri, Brasil

E-mail: samuelsilveira100@gmail.com

Espedito Fidelis de Araújo

ORCID: https://orcid.org/0000-0002-7782-4767

Absolute Christian University, Estados Unidos da América

E-mail: espeditoastro@gmail.com

Cícera Vitória Marcelino Barros

ORCID: https://orcid.org/ 0000-0002-4877-3024

Faculdade de Ciências Humanas do Sertão Central, Brasil

E-mail: cícera.barros@ fachusc.com

Maraiza Gregorio de Oliveira

ORCID: https://orcid.org/ 0000-0002-2855-641X

Universidade Regional do Cariri, Brasil

E-mail: maraaiza0104@hotmail.com

Luciano Temoteo dos Santos

ORCID: https://orcid.org/ 0000-0002-9215-6832

Universidade Federal do Cariri, Brasil

E-mail: luciano.temoteosantos@ gmail.com

Raimundo Samuel Leite Sampaio

ORCID: https://orcid.org/0000-0002-1902-3064

Universidade Regional do Cariri, Brasi

E-mail: samsampaio@hotmail.com

Viviane Bezerra da Silva

ORCID: https://orcid.org/ 0000-0003-0581-2609

Universidade Federal de Pernambuco, Brasil

E-mail: viviane_silvabezerra@hotmail.com 


\begin{abstract}
Resumo
A ciência apresenta muitos traços de correntes filosóficas que existiram na história da humanidade, dentre elas o positivismo. Essa corrente originada no iluminismo tem características marcantes onde a ciência é considerada como uma verdade absoluta, entretanto sabe-se da sua dinamicidade. O objetivo deste trabalho foi evidenciar essas manifestações na educação científica em uma escola de educação básica de Quixelô, Ceará. Para tanto, foram aplicados questionários a alunos do Ensino Fundamental para a coleta de dados. Foi evidenciado que na escola existem correntes positivistas concernentes à educação científica, isto pode ser evidenciado devido os alunos acreditarem que a ciência é uma verdade absoluta, de modo que apresenta respostas concretas e imutáveis. Sendo assim, percebemos que a corrente positivista está presente na educação básica, sendo necessário a explanação por parte dos docentes de como a ciência está em constante ressignificação.Incluir o resumo.
\end{abstract}

Palavras-chave: Educação básica; Positivismo; Ciências; Ensino.

\begin{abstract}
Science has many traces of philosophical currents that existed in the history of humanity, among them positivism. This current originated in the Enlightenment has striking characteristics where science is considered an absolute truth, however its dynamism is known. The objective of this work was to highlight these manifestations in science education at a basic education school in Quixelô, Ceará. For that, questionnaires were applied to elementary school students for data collection. It was evidenced that in the school there are positivist currents concerning scientific education, this can be evidenced because the students believe that science is an absolute truth, so that it presents concrete and immutable answers. Thus, we realize that the positivist current is present in basic education, and it is necessary for teachers to explain how science is in constant resignification.
\end{abstract}

Keywords: Basic education; Positivism; Sciences; Teaching.

\title{
Resumen
}

La ciencia tiene muchas huellas de corrientes filosóficas que existieron en la historia de la humanidad, entre ellas el positivismo. Esta corriente originada en la Ilustración tiene características llamativas donde la ciencia es considerada una verdad absoluta, sin embargo se conoce su dinamismo. El objetivo de este trabajo fue resaltar estas manifestaciones en la educación científica en una escuela de educación básica en Quixelô, Ceará. Para eso, se aplicaron cuestionarios a estudiantes de primaria para la recolección de datos. Se evidenció que en la escuela existen corrientes positivistas en torno a la educación científica, esto se puede evidenciar porque los estudiantes creen que la ciencia es una verdad absoluta, por lo que presenta respuestas concretas e inmutables. Así, nos damos cuenta de que la corriente positivista está presente en la educación básica, y es necesario que los profesores expliquen cómo la ciencia está en constante resignificación.

Palabras clave: Educacion basica; Positivismo; Ciencias; Enseñando.

\section{Introdução}

Quando analisamos o mundo ao nosso redor com os olhos centrados no sistema capitalista, mentalizamos o progresso da Ciência de forma veemente. Essa é o maior e mais importante para o progresso da humanidade, pois onde quer que estejamos a Ciência nos alcança, seja por meio de um aparelho celular, um novo antibiótico, ou um novo planeta descoberto, sendo, portanto, o melhor caminho para se entender o mundo (Reis, 2006).

O termo ciência, deriva do latim que significa conhecimento ou saber. Os conhecimentos adquiridos a respeito da ciência se dão através do estudo teórico e/ou da prática. Nela cabem vários ramos do saber, que são baseados em comprovações ou teorias através de princípios lógicos e racionais (Saviani, 2017). Consequentemente, o que conhecemos hoje como ciência é fruto de mudanças radicais e aperfeiçoamento de conhecimentos durante décadas.

Quando nos retratamos ao conhecimento científico logo em seus passos iniciais, percebe-se que havia barreiras que o desconectava da sociedade. Enquanto a primeira era baseada apenas em experimentos para satisfazerem curiosidades de amadores e profissionais, a segunda não tinha contato direto com o fazer ciência, consequentemente, não havia educação científica. Esse período ficou conhecido como iluminismo, em que se baseava em uma atitude de superioridade relativo à ciência (Pereira, 2007). 
No mesmo período do iluminismo, por volta de meados do século XIX, houve o surgimento de uma corrente de pensamento filosófico denominada de positivista. Esta se baseava no princípio de que o conhecimento científico devia ser reconhecido como o único conhecimento verdadeiro e absoluto, o mesmo não poderia ser contestado (Galvão et al., 2016).

O maior ícone do positivismo foi Auguste Comte (1798-1895), ele formulou três fases da evolução do pensamento humano: o teológico, o metafísico e o positivo. Contudo, considerava o último como importante para o desenvolvimento da sociedade (Mesquida, 2001). Vários autores consideram que Comte foi o pioneiro nas correntes positivistas, mas de acordo com Iskandar e Leal (2002), ele foi influenciado por vários outros pensadores, como por exemplo, Turgot, Condercet e SaintSimon.

A partir do positivismo de Comte a Educação Científica passa a ser essencial na Educação geral, pois compreende-se que através dela a ordem social se estabelece (Souza, 2020). Todavia, para que a Educação Científica seja empregada nos níveis de educação de forma precisa, torna-se fundamental que a Ciência não seja compreendida como uma verdade absoluta, mas um conhecimento que está em constante processo de descobertas e mudanças.

A Educação Científica tem sido alvo de vários debates, sobretudo no modo como ela ocorre no ensino básico público de nosso país. De acordo com Roitman (2007), a educação científica, é ministrada apenas no ensino médio por meio de disciplinas tais como Biologia, Química e Física. Entretanto, esse ensino é de baixa qualidade por diversos fatores, dentre eles está à má formação docente, ausência de laboratórios, material pedagógico desatualizado, carga horária exaustiva e o baixo salário.

De acordo com Galvão et al. (2016) a ciência apresenta muitos traços de correntes filosóficas que existiram na história da humanidade. Exemplo disso é o pensamento positivista que impera nos mais variados níveis de ensino da Educação Básica brasileira. Por não haver uma preocupação por parte das coordenadorias regionais de educação quanto às manifestações dessas correntes nas escolas de ensino básico, com este trabalho objetivou-se evidenciar a manifestação positivista no que concerne à educação científica em uma escola de ensino fundamental da cidade de Quixelô - Ceará, contribuindo assim, para um maior entendimento do que leva a permanência do positivismo na educação.

\section{Metodologia}

O estudo foi desenvolvido em uma escola pública municipal da cidade de Quixelô - Ceará, Brasil. A fim de preservar a identidade da escola o seu nome não foi indicado no estudo.

Foi realizada a pesquisa-ação que segundo Thiollent (2011) consiste em um tipo de pesquisa social com base empírica que é efetuada em consonância com uma ação ou com a busca de soluções para problemas coletivos, onde os pesquisadores e os voluntários estão envolvidos de forma ativa e participativa. A coleta de dados foi realizada com a aplicação de um questionário (Figura 1) com alunos do Ensino Fundamental II.

O questionário foi aplicado a 100 alunos. Foram apresentadas oito questões objetivas referentes à biologia, física e química, tratados neste artigo como Ciências, tendo como foco a investigação da influência da corrente positivista no ensino de ciências ministrado a esses alunos. De posse dos questionários respondidos, foram realizadas as análises dos resultados brutos. A análise estatística foi realizada utilizando o programa GraphPad Prism 6. 
Figura 1. Questionário aplicado aos alunos do ensino fundamental.

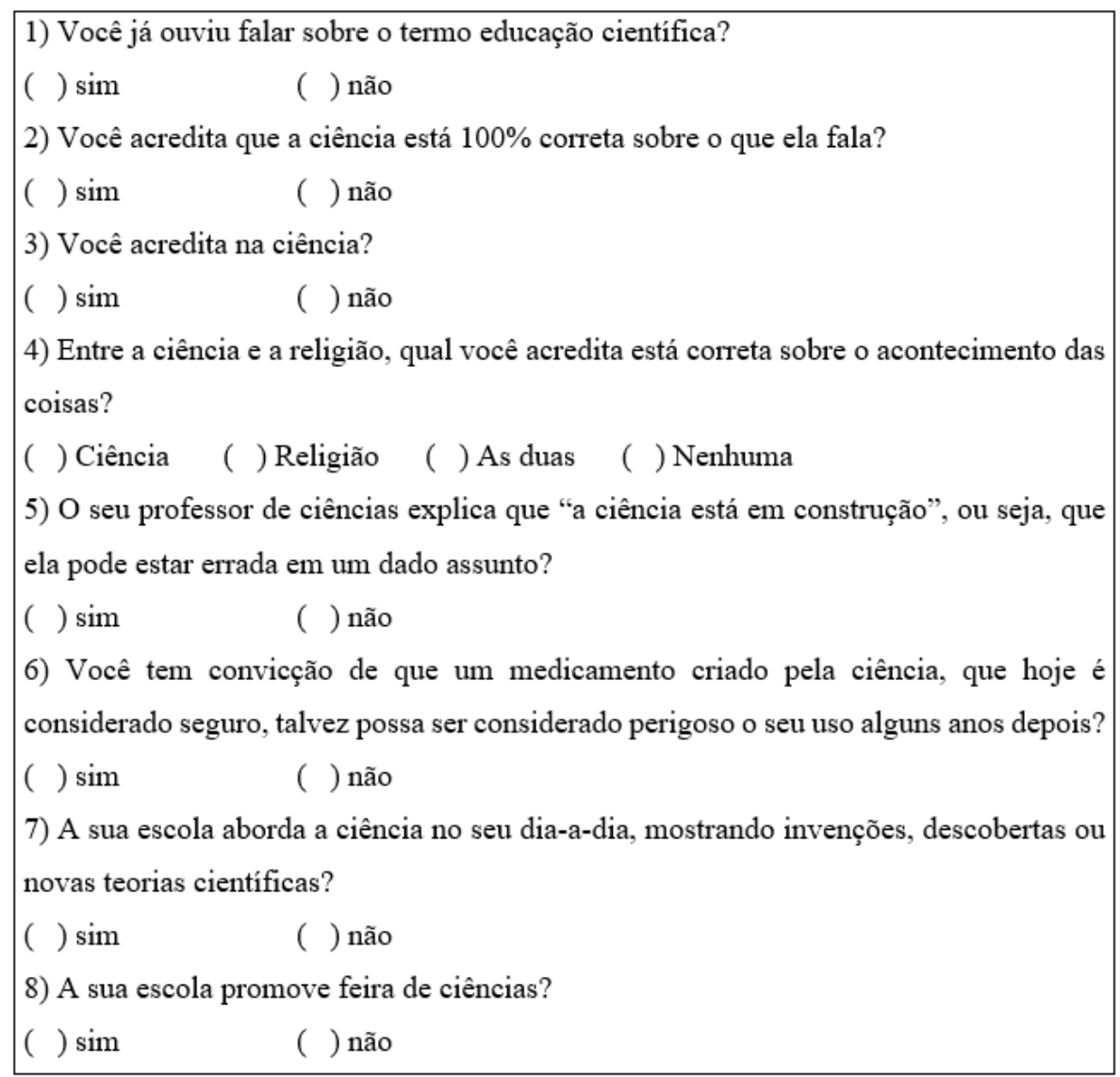

Fonte: Autores (2018).

\section{Resultados}

O primeiro questionamento foi referente à educação científica, essa pergunta traz à tona uma das vertentes deste trabalho, de acordo com os resultados 23 alunos responderam que já ouviram falar no termo educação científica, enquanto 77 responderam que nunca ouviram falar no termo (Figura 2). Isso pode ser justificado por a escola ser de zona rural de uma cidade que não tem muitos recursos voltado para à Ciência, mas sim para outas áreas tais como atividades esportivas.

Figura 2. Questionário aplicado aos alunos do ensino fundamental.

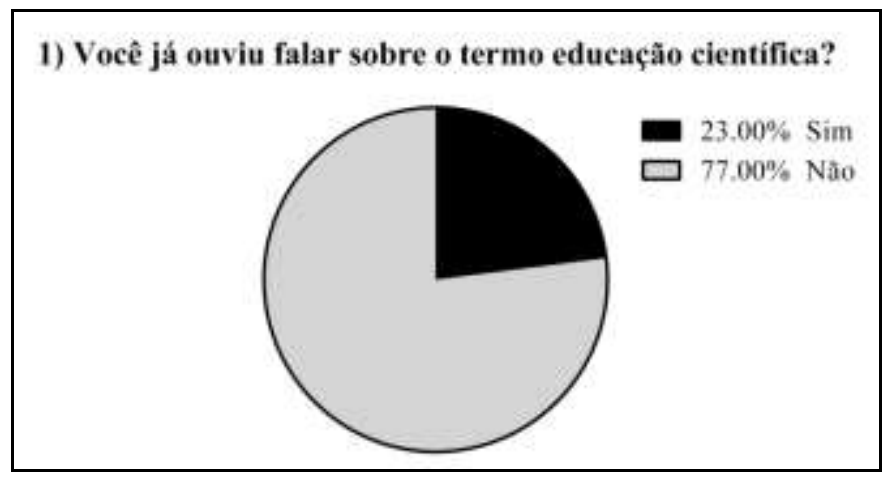

Fonte: Autores (2018).

A segunda pergunta teve por finalidade analisar de modo direto a influência do positivismo na aprendizagem de ciências pelos alunos. De acordo com os dados a grande maioria respondeu que acredita que a ciência está correta sobre tudo 
aquilo que ela fala, totalizando $83 \%$ dos alunos questionados. Apenas uma minoria de $17 \%$ respondeu que não acredita totalmente na ciência. Tem-se uma hipótese quanto a esta minoria, é que de fato esses alunos conhecem bem o que é ciência, seja por algum docente ter demonstrado ou citado em sala de aula ou que tenha sido por meio da leitura de panfletos, livros, revistas ou a própria internet.

Figura 3: Gráfico percentual referente à segunda pergunta.

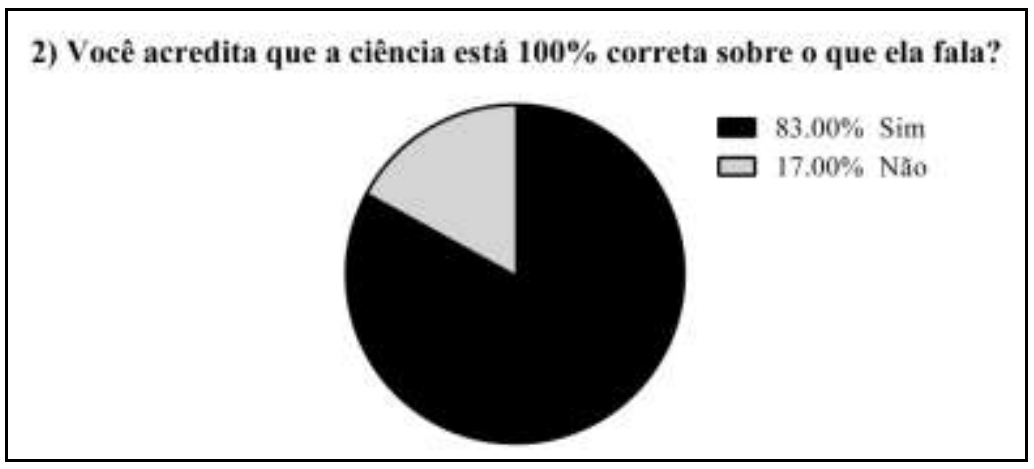

Fonte: Autores (2018).

A terceira pergunta é semelhante à anterior, entretanto ela difere em um ponto, pois enquanto a anterior se detinha à crença na ciência por completo, está se refere à crença na ciência de modo parcial. Podemos ver de acordo com a Figura 4 que há uma diferença na porcentagem quando comparada com a segunda pergunta. Apenas 2 alunos responderam que não acreditam na ciência, enquanto 98 dos alunos responderam que sim.

Figura 4. Gráfico percentual referente à terceira pergunta.

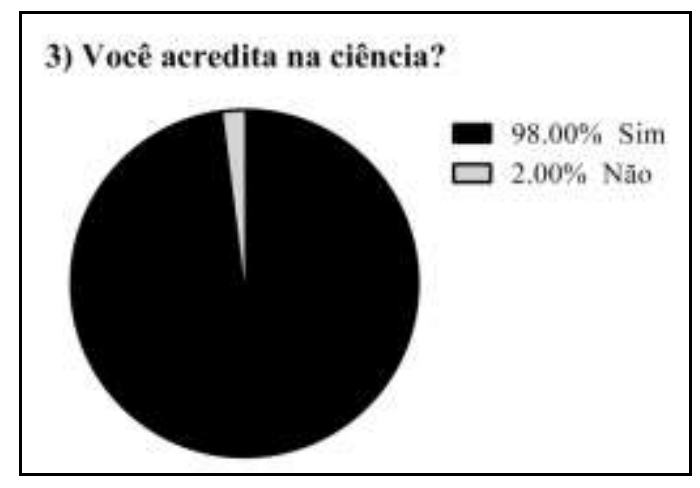

Fonte: Autores (2018).

Algo que poderia estar "interferindo" nos resultados seria a questão da religião dos estudantes, pois muitas religiões tratam a ciência como algo ruim que poderá interferir na vida espiritual dos seus adeptos e não-adeptos. Sendo assim, o quarto questionamento teve por objetivo analisar se a religião dos alunos estava tendo alguma influência nas suas perspectivas quanto à Ciência. De modo geral foi possível observar que não houve uma interferência da religião, pois o questionamento era "Entre a ciência e a religião, qual você acredita está correta sobre o acontecimento das coisas?”, 94\% dos questionados afirmaram que acreditavam na Ciência e na religião, $1 \%$ respondeu que acreditam apenas na Ciência e os demais (5\%) acreditavam apenas na religião. Assim fica evidente que a religião não apresentou interferência no que os alunos acreditavam (Figura 5). 
Figura 5. Gráfico percentual referente à quarta pergunta

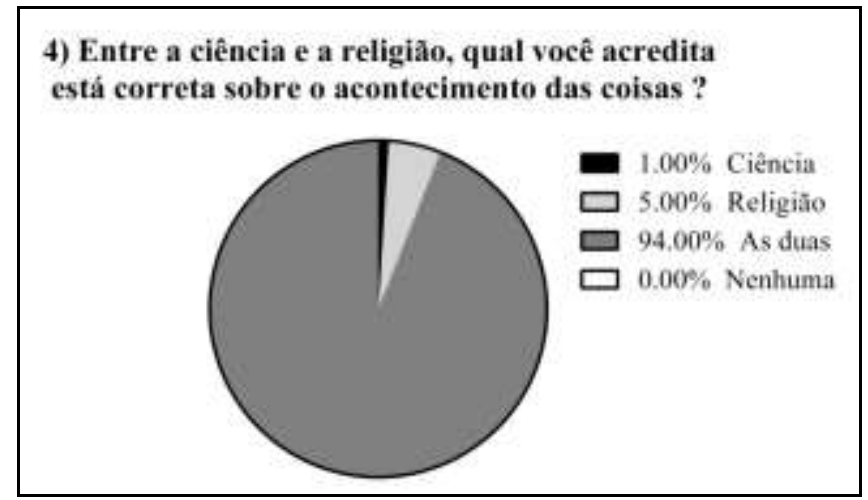

Fonte: Autores (2018).

Em seguida os alunos foram indagados se os seus professores explicavam nas aulas que a Ciência é uma disciplina que sempre está em construção, ou seja, que ela não é uma verdade absoluta. Com as respostas obtidas foi possível analisar que o ensino de ciências apresenta características positivistas fortes, pois um total de $84 \%$ afirmou que seus professores não deixavam isso claro em sala de aula.

Uma análise foi realizada voltando a pergunta para o dia-a-dia dos discentes. A pergunta consistia em: "Você tem convicção de que um medicamento criado pela ciência, que hoje é considerado seguro, talvez possa ser considerado perigoso o seu uso alguns anos depois?". Essa pergunta avaliou se as questões positivistas apresentavam marcas de como os alunos imaginavam "A Ciência" no dia-a-dia. Como nas perguntas anteriores os alunos se mostraram com traços positivistas nesse caso não foi diferente. Um total de 89 alunos responderam que não tinha convicção de que um remédio poder ser considerado inseguro no futuro, enquanto apenas 11 alunos tinham conviç̧ão disso.

Uma forma da educação científica não apresentar fortes traços da corrente já citada é mostrar aos alunos novas invenções, descobertas e teorias. Quando os alunos já apresentam uma boa base teórica científica estes estão sujeitos confrontar as informações antigas com as novas e eles perceberão que há sempre mudanças quanto à Ciência. Uma forma de apresentar essas novas teorias e descobertas são folhetins em murais chamativos dentro do âmbito escolar. No estudo foi questionado aos estudantes se a escola abordava a ciência no seu dia-a-dia, mostrando invenções, descobertas ou novas teorias científicas, uma minoria respondeu que sim, representando apenas 19\%, enquanto $81 \%$ da amostragem responderam que não.

Outro modo eficaz da escola poder mostrar aos alunos a verdadeira ciência é por meio de eventos, mesmo os de pequeno porte já fariam diferença nesse entendimento, então na última questão foi perguntado se a escola promovia feira de ciências. Todos os alunos responderam que não, ficando assim evidente que a escola não utiliza de muitos instrumentos que possam mostrar a Ciência como sendo dinâmica e inovadora.

Observa-se que os estudantes dessa escola apresentam possuem um conhecimento da Ciência pautados, sobretudo, em traços da corrente positivista.

\section{Discussão}

Devido o positivismo ter sido acentuado no século XIX, não havia uma educação científica de modo efetivo, ela era estagnada pelo o que os empiristas (positivistas) ditavam na época. Pois o que era ditado era lei, logo não podia ser contestado, e a educação científica não se trata apenas de aprender conceitos ou técnicas, mas sim da construção e reconstrução do conhecimento (Sasseron; Carvalho 2016).

Um grande problema por qual a Educação científica ainda passa é que a mesma apresenta traços positivistas, uma corrente teórica que não admite a ciência como algo em construção, algo que possa ser modificado. Alguns cientistas lutaram 
contra essa corrente, tais como Karl Popper, Thomas Kuhn e Imre Lakatos, em que eles admitiam a ciência como algo efêmero, que não apresenta uma constância, eles foram denominados de racionalistas (pós-positivistas) (Pereira, 2007).

Por haver essas características na Educação científica, o modo de se ensinar ciências vem sendo empregado de maneira incorreta por professores, pois eles aprendem durante suas formações docentes que a ciência é algo infalível, algo indiscutível, interferindo negativamente no modo de produzir e de ensinar a própria ciência. Isso acontece por que muitas vezes a sua graduação é do tipo tradicional tecnicista (Fourez, 2016).

Além disso, outro motivo para que os docentes apresentem traços positivistas é que os mesmos não tiveram contato direto durante sua graduação com programas de iniciação científica, como é o caso do Programa Institucional de Bolsas de Iniciação Científica (PIBIC) fomentado pelo Conselho Nacional de Desenvolvimento Científico e Tecnológico (CNPq). Para quem é bolsista do PIBIC/CNPq tem um contato direto do que é a verdadeira ciência, em que o aprendizado é adquirido por meio de erros e tentativas, assim como também por meio da leitura, em que a prática, junto com a teoria trazem base para o que é o conhecimento científico (Pires, 2016). Sendo assim, os estudantes condicionados a estudarem Ciências com professores que possuem traços positivistas possuem grandes chances de construírem seus conhecimentos científicos pautados no positivismo.

A leitura é a ferramenta chave para a educação científica, no caso dos bolsistas PIBIC, eles percebem por meio da leitura que a ciência não é uma verdade absoluta, pois irão observar que as teorias mudam com o passar do tempo. Sendo assim, o que é afirmado hoje pode ser contestado lá no futuro e ser incorporado mais ideias ou até mesmo substituída (Sasseron; Carvalho 2016). Tomemos como exemplo a teoria da evolução, o pioneiro nesses estudos foi Lamarck, em que a sua teoria se baseava no "uso e desuso", posteriormente ela foi substituída pela teoria de Darwin-Wallace. Em que isso não significa que a teoria de Darwin-Wallace está correta até o "fim dos tempos", mas ela será acolhida pela sociedade científica até um dado momento, até que um cientista/pesquisador venha a complementar as ideias ou substituí-las.

É necessário que haja um maior comprometimento dos professores quanto a desassociação do ensino de ciências ao positivismo, pois este possui características que dificultam a construção do conhecimento científico. Estudo realizado por Chizzotti (2016) indica que os discentes que têm contato apenas com professores positivistas apresentam tendências dessa corrente, seja no seu dia-a-dia como estudante ou até mesmo no futuro como um profissional.

É notório que boa parte dos estudantes do ensino fundamental ainda estão muito conectados as suas concepções alternativas. Nesse sentido, faz-se necessário a desconstrução e ressignificação dessas concepções através da alfabetização científica para que possam desenvolver-se integralmente quanto indivíduos críticos e atuantes.

A falta de divulgação científica no ambiente escolar pode desfavorecer a alfabetização científica e favorecer o estabelecimento de traços positivistas na concepção dos estudantes quanto a ciência. Visto que a incorporação de atividades de divulgação científica nas escolas enquanto são grandes aliadas no processo de aprendizagem, pois além de evitar as interpretações equivocadas dos fatos científicos favorece uma visão abrangente a respeito dos assuntos estudados (Xavier; Gonçalves, 2014).

De acordo com Roitman (2007) é através da educação científica que se desenvolve habilidades, define conceitos e conhecimentos, causando estimulo ao indivíduo no que se refere a observar, questionar, investigar, explicitar e compreender de maneira lógica e concisa os seres vivos, o meio em que vivem e os eventos do dia-a-dia. Se compararmos ao ensino atual da educação básica, onde os alunos não são instigados a investigar causas, mas sim aprender termos técnicos em livros, vemos explicitamente que não há o progresso na alfabetização científica.

No século atual, a educação científica é vista como essencial para a formação de cidadãos críticos. Contudo, o desafio maior não consiste em "transmitir" o conhecimento, mas produzi-lo dentro das Instituições de Ensino. A educação científica não está restrita apenas à sala de aula, ela também pode estar presente em espaços não formais, tais como museus, laboratórios, 
herbários, planetários, etc. Sendo assim, os problemas que esse tipo de educação enfrenta, ultrapassa as paredes da sala de aula.

\section{Conclusão}

Diante do exposto, fica evidente que a educação científica na escola estudada, apresenta traços da corrente positivista e por não serem trabalhadas dentro da sala de aula de forma satisfatória, perpassa os anos letivos tornando-se um problema recorrente.

É evidente que os docentes precisam repensar a sua prática de ensino para que o processo educacional seja transformador. Todavia, é necessário que mais ações sejam pensadas pelos órgãos que regem a educação no sentido de dar suporte ao professor, tanto em melhores condições de trabalho quanto em formação continuada.

Destarte, tendo em vista a importância de estudos voltados para o entendimento da educação científica desde a Educação Básica, faz-se necessário a realização de novas pesquisas para que possam adotar práticas voltadas para a propagação do conhecimento científico e consequentemente, a formação de indivíduos críticos, capazes de analisar e transformar positivamente suas realidades.

\section{Referências}

Almeida, M. A., \& Machado, V. L. C. (2012). Ideologia e ciência social. Revista de Educação PUC-Campinas, 23(1), 151-158.

Chizzotti, A. (2016). As Ciências Humanas e as Ciências da Educação. Revista e-Curriculum, 14(4), 1556-1575.

Fourez, G. (2016). Crise no ensino de ciências? Investigações em ensino de ciências, 8(2), 109-123.

Galvão, K. D. S., Silva-Neto, O. S., Santos, J. F. D., \& Raboni, P. L. (2016). Análise dos modelos de precificação de ativos sob uma abordagem epistêmica do positivismo/pós-positivismo e do construtivismo. Cadernos EBAPE. BR, 14(1), 228-242.

Iskandar, J. I., \& Leal, M. R. (2002). Sobre positivismo e educação. Revista Diálogo Educacional, 3(7), 89-94.

Mesquida, P. Educação brasileira. Apostila do Curso de Mestrado em Educação. Pontifícia Universidade Católica do Paraná, Curitiba, 2001.

Nacionais, Parâmetros Curriculares (Ensino Médio). (1999). Brasília: Ministério da Educação, 538-545.

Pereira, D. C. (2007). Nova educação na nova ciência para a nova sociedade. Fundamentos de uma pedagogia científica contemporânea (volume 1). Porto: Editora da Universidade do Porto.

Pires, R. C. M. (2016). Iniciação científica e avaliação na educação superior brasileira. REXE-Revista de Estudios y Experiencias en Educación, 1(1), 137-160.

Reis, P. (2006). Ciência e educação: que relação? Interacções, 2(3), 160-187.

Roitman, I. (2007). Educação científica: quanto mais cedo melhor. Brasília, Brasil: RITLA.

Sasseron, L. H., \& Carvalho, A. M. P. (2016). Alfabetização científica: uma revisão bibliográfica. Investigações em ensino de ciências, $16(1)$, $59-77$.

Saviani, D. (2017). Epistemologias da política educacional: algumas precisões conceituais. Revista de Estudios Teóricos y Epistemológicos en Política Educativa, 2(s/v), 1-5.

Souza, D. C. (2020). O Positivismo de Auguste Comte e a educação científica no cenário brasileiro. REAMEC-Rede Amazônica de Educação em Ciências e Matemática, 8(1), 29-42.

Thiollent, M. (2011). Metodologia da Pesquisa-ação. Cortez.

Xavier, J., \& Gonçalves, C. (2017). A relação entre a divulgação científica e a escola. Revista Amazônica de Ensino de Ciências, 7(14), 182-189. 